\title{
LXXIII. On the depolarization of light
}

\section{Professor Dove}

To cite this article: Professor Dove (1847) LXXIII. On the depolarization of light, Philosophical Magazine Series 3, 30:204, 469-470, DOI: 10.1080/14786444708645760

To link to this article: http://dx.doi.org/10.1080/14786444708645760

曲 Published online: 30 Apr 2009.

Submit your article to this journal 준

Џll Article views: 4

Q View related articles ¿ 
13. A rotating velocity, which continues to decrease and increase through an entire revolution, in (1) and (9) produces partially polarized instead of ordinary light.

14. Unannealed glasses rotating between Nichol's prisns at rest, do not neutralize each other and form white light.

15. Light from a rotating Nichol's prism falling upon a metallic mirror, possesses the ordinary characters.

16. The twin-growth of crystals gives rise to very complicated phrnomena of colour. This is very beautifully scen in plates of calcareous spar, ground at right angles to the axis of the inclosing individual. The author has formed some of them artificially, by introducing a lamina of selenite of a definite thickness between two accurately centred plates*. If a plate of a natural twin-crystal be rotated, after having been accurately centred as regards the axis of rotation, the colours become neutralized, forming white light ; whilst a simple plate, rotated on its axis, preserves its system of rings unchanged.

N.B. [The phænomena of interrupted crystals, described in paragraph 16 of this paper, were observed by Sir David Brewster previous to 1819 ; and the method of forming them artificially by enclosing laminæ of selenite and mica between accurately centred plates of calcareous spar, and between equal plates of the spath calcaire basée, was practised by him previously to March 1827, the date of which is signed, in his Journal of Experiments, by the Vice-President of the Royal Society of Edinburgh. The experiments, too, are briefly described in his Treatise ou Optics, Part II. chap. xxii. \$115, p. 197.-Eo.]

LXXIII. On the Depolarization of Light. By Prof. Dove. TF rectilinearly polarized light be allowed to fall upon a 1 rough surface, as a white wall, it is perfectly depolarized. This phænomenon is most distinctly seen, by allowing the spectra of a prism of rock-crystal, polarized at right angles to each other, to fall upon such a surface, and analysing the purple-red resulting from the violet end overlapping the red extremity, with a Nichol's prism. On rotating the latter, there is not the slightest alteration in colour. This depolarization, which eight years ago the author, in a paper communicated to the Berlin Society of Friends of Natural History, showed also to occur on the rough internal surface of bodies covered with a reflecting layer, progressively diminishes with the obliquity of the incidence, so that even the dullest surface ceases to depolarize at very acute incidences. With perpendicular incidence, it also extends to circular and elliptical light, which, when reflected by a rough surface, is depolarized, $i$.e. possesses the properties of common light. If the explanation of the depolarizing property of rough surfaces is found in the supposition that such a surface reflects in all directions, by the converse, the combination of light polarized in all possible

* Poggendorff's Annalen, vol. xxxv. p. 594. 
planes yields common light by reflexion. A truncated hollow cone, the smaller circular section of which was about fourteen lines in diameter, and the larger seventeen lines, was ground into a glass plate, four lines in thickness and three inches in diameter. The lowermost surfaces of the glass were roughened at the margin of the circular section and blackened, and the larger circular section was covered with a glass plate, upon which a circular piece of tin-foil was pasted, so that its centre coincided with the axis of the truncated cone. The angle of the cone at the apex amounted to $70^{\circ} 50^{\prime}$. When this apparatus is turned towards the sun, so that the rays fall at right angles to the base of the cone, they enter the annular space between the tin-foil and the dark coating of the sheath, and arrive at the reflecting surface of the hollow cone at an angle of $35^{\circ} 25^{\prime}$, thus becoming polarized in all the planes of reflexion, and after reflexion, crossing at one point of the axis. In the apparatus made by CErtling, this point was exactly in the plane of the smaller aperture of the cone, and was visible when received upon the surface of a piece of white paper placed there. As the polarized light would be depolarized on account of the depolarizing action of this rough surface, it could only be determined that it was unpolarized. This was effected by polarizing the light incident upon the cone by means of an inserted glass plate, and introducing a plate of mica between the inserted glass plate and the cone. The point remained colourless.

LXXIV. On Thialdine and Selenaldine, two new artificial organic bases. By Wöhler and Liebig. Communicated by Dr. A. W. HofmanN *

\section{Thialdine.}

THE peculiar deportment of hydrated cyanic acid with aldehyde, which gives rise to a new acid containing the elements of aldehydite of ammonia and hydrated cyanic acid, induced us to study the action of some other substances on aldehyde and aldehydite of ammonia.

The most interesting product which we obtained along with others, is a new organic alkali free from oxygen, and containing carbon and hydrogen in the same proportions as acetic acid, combined with sulphur and the elements of sulphide of ammonium. This substance, which we call thialdine $\phi$, is highly remarkable from its composition, and we have no doubt that the method which led to its discovery, when applied to other compounds analogous to aldehyde and aldehydite of ammonia, will yield a long series of new and inter-

* Communicated by the Chemical Society; having been read January 4, 1847.

$\uparrow$ Contracted from $\theta \in i o \nu$ and aldehyde. 